\title{
BMJ Open Purpose in life and tobacco use among community-dwelling mothers of early adolescents
}

\author{
Yuko Morimoto, ${ }^{1}$ Syudo Yamasaki, ${ }^{1}$ Shuntaro Ando, ${ }^{1,2}$ Shinsuke Koike, ${ }^{3}$ \\ Shinya Fujikawa, ${ }^{2}$ Sho Kanata, ${ }^{4}$ Kaori Endo, ${ }^{1}$ Miharu Nakanishi, ${ }^{1}$ \\ Stephani L Hatch, ${ }^{5}$ Marcus Richards, ${ }^{6}$ Kiyoto Kasai, ${ }^{2}$ Mariko Hiraiwa-Hasegawa, ${ }^{7}$ \\ Atsushi Nishida ${ }^{1}$
}

To cite: Morimoto Y, Yamasaki S, Ando $\mathrm{S}$, et al. Purpose in life and tobacco use among community-dwelling mothers of early adolescents. BMJ Open 2018;8:e20586. doi:10.1136/ bmjopen-2017-020586

- Prepublication history for this paper is available online. To view these files, please visit the journal online (http://dx.doi. org/10.1136/bmjopen-2017020586).

YM and SY contributed equally.

Received 10 November 2017

Revised 2 March 2018

Accepted 9 March 2018

Check for updates

For numbered affiliations see end of article.

Correspondence to

Dr Atsushi Nishida;

nishida-at@igakuken.or.jp

\section{ABSTRACT}

Objectives The rising prevalence of tobacco use and tobacco-attributable deaths among women is of worldwide concern. In particular, smoking prevention for mothers in early midlife is a significant international public health goal. A higher sense of purpose in life (PIL) is thought to reduce detrimental health behaviours. However, little is known about the association between a sense of PIL and tobacco use. This study investigates this association among community-dwelling mothers of early adolescents. Design This population-based cross-sectional study uses a self-reported questionnaire from the Tokyo Early Adolescence Survey, a large community-based survey conducted in Japan between 2012 and 2015.

Setting Participants were randomly recruited from the resident registries of three municipalities in Tokyo, Japan. Participants A total of 4478 children and their primary parents participated. Responses from 4063 mothers with no missing data were analysed (mean age $=42.0$ years $(\mathrm{SD}=4.2))$.

Measures Participants' tobacco use, including the number of cigarettes smoked per day, was documented using a questionnaire. PIL was assessed using a Purpose in Life scale derived from Ryff's Psychological Well-Being Scale.

Results Greater PIL was associated with a decreased likelihood of tobacco use, even when adjusted for confounders $(\mathrm{OR}=0.80,95 \% \mathrm{Cl} 0.70$ to 0.91$)$. Multinomial logistic regression analyses revealed that PIL was inversely associated with tobacco consumption among mothers. These associations remained after controlling for psychological distress, socioeconomic factors and frequency of alcohol consumption among moderate to heavy smokers $(0 \mathrm{R}=0.70,95 \% \mathrm{Cl} 0.57$ to 0.86$)$, while attenuated among light smokers.

Conclusions Increasing PIL may be a valuable intervention for reducing tobacco use among women in early midlife. This study can contribute to our understanding of the psychology of smoking behaviour and shed light on the targeted intervention to reduce tobacco use among early midlife mothers.

\section{INTRODUCTION}

The tobacco epidemic is one of the most significant international public health
Strengths and limitations of this study

- The study investigated the association between a sense of purpose in life (PIL) and tobacco use among community dwelling mothers in early midlife.

- Data were collected from a large community-based sample of mothers in early-middle age, randomly recruited from the resident registries of three municipalities in Tokyo.

- We demonstrated the association between PIL and tobacco use while controlling for confounders, including demographic variables and psychological distress.

- The study adopted a cross-sectional design and was limited to determining a causal relationship between PIL and tobacco use.

threats. Globally, more than 1 in 10 adult deaths is estimated to be due to tobacco. The WHO is particularly concerned about the possibility that the global increase in deaths due to tobacco is driven by the accelerating rate of tobacco use in women. ${ }^{1}$ Smoking prevalence among women is not decreasing, while that among men has been decreasing rapidly during the past three decades in Japan. ${ }^{2}$ Tobacco use among women is dramatically increasing among those aged between 30 and 50 years old, ${ }^{3}$ and tobacco cessation in early midlife is associated with a substantial decline in mortality risk for women. ${ }^{45}$ In addition, maternal smoking is the major determinant of child's passive smoking ${ }^{6}$ and smoking initiation. ${ }^{7}$ Smoking prevention for women, especially mothers, in early midlife, is therefore a significant international public health goal.

We examined the association between purpose in life (PIL) and tobacco use in women in early midlife. PIL is a component of psychological eudaemonic well-being, and refers to the extent to which individuals regard their own life as meaningful. ${ }^{8}$ 
Previous studies, which have mainly examined elderly populations, have shown that a higher sense of PIL is associated with reduced risk for diseases (eg, Alzheimer's disease,${ }^{9}$ myocardial infarction, ${ }^{10}$ stroke,${ }^{11}$ cerebral infarctions ${ }^{12}$ ) and with better physical function ${ }^{13}$ and lower mortality. ${ }^{14-19}$ A growing body of research indicates the existence of links between PIL and health behaviours ${ }^{20}$ (eg, use of preventive healthcare services, ${ }^{21}$ daily exercise,${ }^{22-24}$ maintenance of a healthy diet, ${ }^{25}{ }^{26}$ preventive behaviours for breast cancer) ${ }^{23}$ Recent systematic review showed that greater PIL is related to a range of better health outcomes for older adults. ${ }^{27}$ The significance of PIL on better health is recently recognised cross-culturally (eg, Ikigai in Japanese). Recent evidence demonstrated that PIL was associated with healthy glucoregulation among Japanese adults, ${ }^{28}$ which had also demonstrated in Western countries. ${ }^{29}$ In contrast, lower PIL is associated with detrimental health behaviours. Previous research in this area has mainly concentrated on the association between PIL and addiction. ${ }^{30-33}$

Previous studies suggested that interventions and promotions focusing on psychological factors were important for smoking prevention and cessation among women. Meta-analyses have shown that women have more difficulty maintaining long-term smoking cessation than men, ${ }^{34}$ and nicotine replacement therapy for smoking cessation is less effective in women than in men, in particular for supporting long-term maintenance of smoking cessation. ${ }^{35}$ Another meta-analysis demonstrated that motivational interviewing, which is a psychological approach used to enhance PIL among people with addictive behaviours, could be effective for tobacco cessation. ${ }^{36}$

PIL might be a significant psychological factor for promoting tobacco cessation among women. However, relatively little is known about the association between PIL and tobacco use, with no study to date examining this association in women in early midlife. A previous survey on 341 adults in Hungary ${ }^{37}$ demonstrated that daily smokers had lower PIL than non-smokers, although the sample was limited to a small number and did not focus on women in early midlife. In the current study, we hypothesised that PIL is inversely associated with tobacco use among early midlife mothers, even after controlling for demographic variables and the effect of psychological distress. Psychological distress (depression and/ or anxiety) often co-occurs with tobacco use. ${ }^{38-45}$ Since psychological distress (ill-being) is inversely associated with PIL $^{84647}$ and is positively associated with substance abuse, ${ }^{31} 32$ it could confound associations between PIL and tobacco use. We also hypothesised that PIL is inversely associated with the amount of tobacco consumption.

\section{METHODS}

\section{Study design, sample and survey procedure}

This study used data from the Tokyo Early Adolescence Survey (T-EAS) ${ }^{48} 49$ which was originally designed as a baseline survey for the Tokyo Teen Cohort, a currently ongoing longitudinal cohort study (http://ttcp.umin. $\mathrm{jp} / \mathrm{index} . \mathrm{html}$ ). The T-EAS is a multidisciplinary survey of 10-year-old adolescents and their primary caregivers (98.5\% mothers). The T-EAS contains questions about tobacco use, PIL and psychological distress, as well as a variety of other potentially confounding variables. Participants were randomly recruited from the resident registries of three municipalities in Tokyo: Setagaya Ward, Mitaka City and Chofu City. Participants were sent invitation letters on or around the child's 10th birthday. The survey was completed in two home visits. During the first visit, written informed consent from the primary caregiver (generally the mother) was obtained; participants were then asked to complete the questionnaires at home before the second visit. During the second visit, both the adolescent and the primary caregiver were each asked to complete the self-report questionnaires separately. The questionnaires were enclosed in envelopes by the respondents immediately after completion. In addition, the primary caregiver responded to a semistructured interview. All data were collected anonymously. The T-EAS was conducted by three research institutes: Tokyo Metropolitan Institute of Medical Science, The University of Tokyo and SOKENDAI (The Graduate University for Advanced Studies). This survey was approved by the ethics committees of these three institutes.

\section{Participants}

A total of 4478 children and their primary parents participated in the T-EAS (response rate 43.8\%). We used the primary parent data for the purposes of the current study. Of the 4478 respondents, 68 were men and were hence excluded to focus the investigation on the association between PIL and tobacco use in women. An additional 347 female respondents' data were excluded due to incomplete answers to the questions on tobacco use, PIL, psychological distress or other confounding variables. The final dataset therefore contained data from 4063 respondents.

\section{Measures}

Tobacco use

Respondents were asked whether they used tobacco. Those who answered 'yes' were subsequently asked about the number of cigarettes they smoked per day. A binary variable was created (' 0 : non-smokers' vs ' 1 : smokers'), based on the first question. Respondents were then split into '0: non-smokers', '1: light smokers (less than half a pack (=10 cigarettes) per day)' and '2: moderate to heavy smokers (more than or equal to half a pack per day)', to assess potential dose-response effects.

\section{Purpose in life}

PIL was assessed using a 14-item version of the Purpose in Life scale derived from Ryff's Psychological Well-Being scales. ${ }^{8}$ The scale included items such as 'I have a sense of direction and purpose in life', and 'My daily activities often seem trivial and unimportant to me' (reverse 
coded). Each item was rated on a 6-point Likert scale (1: strongly disagree; 6 : strongly agree) and scores were summed, so that continuous scores ranged from 14 to 84 . Higher scores indicated a higher sense of PIL.

\section{Psychological distress}

Psychological distress was assessed using the K6. ${ }^{50}$ This survey contains six items, assessing how frequently during the past 30 days respondents felt: (1) so depressed that nothing could cheer them up, (2) hopeless, (3) restless or fidgety, (4) that everything was an effort, (5) worthless and (6) nervous. Each item was scored on a 5-point Likert scale (0: never; 4: most of the time). Scores were summed, with the resulting raw scores ranging from 0 to 24. Higher scores indicate more frequent psychological distress during the past 30 days.

\section{Other covariates}

The following covariates were examined for their potential confounding effects: age, educational attainment, marital status, annual family income and frequency of alcohol consumption. High socioeconomic status (represented by educational attainment and annual family income here) is known to be associated with higher PIL, ${ }^{46}$ and socioeconomic disadvantage is a risk factor for tobacco use.$^{51-54}$ Educational attainment was coded as follows: '1: junior high school or lower', '2: high school', '3: technical or junior college' and '4: 4-year university or higher'. Marital status was dichotomised as '1: yes' or ' 0 : no', depending on whether the respondent was in a marriage or marriage-like relationship. Family income over the past year was divided into four categories: ' 1 : less than 4 million yen', '2: 4-6 million yen', '3: 7-9 million yen' and '4: over 10 million yen'. Frequency of alcohol consumption was assessed using a 5-point Likert scale (0: do not drink; 4: more than four times a week).

\section{Statistical analyses}

Cross tabulation, $\chi^{2}$ tests and residual analyses were conducted to test the differences between three groups based on the amounts of tobacco used (none, light and moderate to heavy smokers), and covariates in categorical variables as well as analyses of variance (ANOVAs) were used in continuous variables. Correlation coefficients among all variables also examined. We conducted binomial logistic regression analyses (using a binary-dependent variable: non-smokers vs smokers) to test the association between PIL and tobacco use. The PIL score was standardised to report ORs per one SD change of PIL scores. Logistic regression model 1 was unadjusted for covariates; model 2 was adjusted for socioeconomic covariates: age, education, marital status and family income; model 3 was further adjusted for alcohol consumption and finally, model 4 was further adjusted for psychological distress. In order to further examine the relationship between PIL and tobacco use, we conducted multinomial logistic regression analyses to assess the effect of PIL on the degree of tobacco use. Regression models 5-8 were identical to models $1-4$, except that the dependent variable was multivariate: non-smokers, light smokers and moderate or heavy smokers.

\section{Patient involvement}

Patients were not involved in developing the study hypothesis, recruitment, outcome measures, study design or implementation. Patients were not involved in interpretation or writing up on the results. There are no plans to disseminate the results of the research to study participants or the relevant patient community.

\section{RESULTS \\ Prevalence of smokers and corresponding descriptive statistics}

Of the 4063 respondents (mean age 42.0 years; SD 4.2; 95.8\% married; $40.1 \%$ achieved a degree from a 4-year university or higher; $8.8 \%$ had family income less than 4 million yen), $324(8.0 \%)$ were smokers. A total of 204 $(5.0 \%)$ were light smokers, $120(3.0 \%)$ were moderate to heavy smokers. $X^{2}$ tests and ANOVA indicated that inverse associations were clearly evident between tobacco use and PIL, age, education, marital status and annual family income (table 1). Residual analyses indicated that lower educational attainment (light smokers with junior high school or lower education (adjusted residuals $=6.9, \mathrm{p}<0.01)$ and those with high school education (adjusted residuals $=6.9, \mathrm{p}<0.01$ ); moderate or heavy smokers with junior high school or lower education (adjusted residuals $=7.0, \mathrm{p}<0.01$ ) and those with high school education (adjusted residuals $=7.6$, $\mathrm{p}<0.01)$ ), not being married (light smokers without being married (adjusted residuals $=4.8, \quad \mathrm{p}<0.01$ ); moderate to heavy smokers without being married (adjusted residuals $=8.3, \mathrm{p}<0.01)$ ), lower family income (light smokers with the lowest family income (less than 4 million yen) (adjusted residuals $=6.1, \mathrm{p}<0.01$ ) and those with the second lowest family income (4 to 6 million yen) (adjusted residuals $=2.6, \quad \mathrm{p}<0.01$ ); moderate to heavy smokers with the lowest family income (adjusted residuals=6.7, $\mathrm{p}<0.01$ ) and those with the second lowest family income (adjusted residuals=4.7, $\mathrm{p}<0.01)$ ) and the most frequent alcohol use (light smokers with the most frequent alcohol consumption (more than four times a week) (adjusted residuals $=6.6, p<0.01$ ); moderate to heavy smokers with the most frequent alcohol use (adjusted residuals $=2.7$, $\mathrm{p}<0.01)$ ) were associated with increasing tobacco use. Psychological distress was higher in smokers than in non-smokers (table 1). On the other hand, the highest alcohol consumption was reported by light smokers (table 1). PIL was positively correlated with age, educational attainment, family annual income while negatively correlated with tobacco consumption and psychological distress (table 2). Tobacco consumption was positively correlated with alcohol consumption and psychological distress while negatively correlated 
Table 1 Descriptive statistics for Tokyo Early Adolescence Survey variables broken down by tobacco use

\begin{tabular}{|c|c|c|c|c|}
\hline & Non-smokers & Light smokers & Moderate to heavy smokers & $P$ values \\
\hline $\mathrm{N}(\%)$ & $3739(92.0)$ & $204(5.0)$ & $120(3.0)$ & \\
\hline Purpose in life, mean (SD) & $57.3(9.7)$ & $54.8(9.8)$ & $52.6(9.9)$ & $<0.001$ \\
\hline Age, mean (SD) & $42.0(4.1)$ & $41.2(5.0)$ & $40.5(4.8)$ & $<0.001$ \\
\hline \multicolumn{5}{|l|}{ Education, n (\%) } \\
\hline Junior high school or lower & $22(0.6)$ & $12(5.9)$ & $9(7.5)$ & $<0.001$ \\
\hline High school & $512(13.7)$ & $66(32.4)$ & $48(40.0)$ & \\
\hline Technical or junior college & $1626(43.5)$ & $89(43.6)$ & $51(42.5)$ & \\
\hline 4-year university or higher & 1579 (42.2) & $37(18.1)$ & $12(10.0)$ & \\
\hline \multicolumn{5}{|l|}{ Marital status, n (\%) } \\
\hline Yes & 3613 (96.6) & $182(89.2)$ & $97(80.8)$ & $<0.001$ \\
\hline No & $126(3.4)$ & $22(10.8)$ & $23(19.2)$ & \\
\hline \multicolumn{5}{|l|}{ Family annual income, n (\%) } \\
\hline Less than 4 million yen & $285(7.6)$ & $42(20.6)$ & $31(25.8)$ & $<0.001$ \\
\hline 4-6 million yen & $1022(27.3)$ & $74(36.3)$ & $57(47.5)$ & \\
\hline 7-9 million yen & $1162(31.1)$ & $55(27.0)$ & $21(17.5)$ & \\
\hline More than 10 million yen & $1270(34.0)$ & $33(16.2)$ & $11(9.2)$ & \\
\hline \multicolumn{5}{|l|}{ Alcohol use, n (\%) } \\
\hline Non & $1160(31.0)$ & $44(21.6)$ & $43(35.8)$ & $<0.001$ \\
\hline Less than once a month & $563(15.1)$ & $35(17.2)$ & $9(7.5)$ & \\
\hline 2-4 times a month & $689(18.4)$ & $24(11.8)$ & $15(12.5)$ & \\
\hline 2-3 times a week & $594(15.9)$ & $21(10.3)$ & $16(13.3)$ & \\
\hline More than four times a week & $733(19.6)$ & $80(39.2)$ & $37(30.8)$ & \\
\hline K6 (psychological distress), mean (SD) & $2.9(3.3)$ & $3.4(3.4)$ & $3.5(3.9)$ & 0.026 \\
\hline
\end{tabular}

with age, educational attainment, marital status and family annual income (table 2). Age, educational attainment and family annual income were positively correlated among each other. Marital status was positively correlated with educational attainment and family annual income. Psychological distress was positively correlated with age, while negatively correlated with marital status and family annual income (table 2).
Association between PIL and tobacco use

Table 3 shows the binominal ORs for tobacco use compared with no smoking. PIL was strongly inversely associated with tobacco use in the analysis without covariates (model 1). The OR was not attenuated after adjusting for socioeconomic variables (model 2). This was also the case after adjusting for alcohol consumption (model 3) and, finally, for psychological distress (model 4). With regard

Table 2 Correlation coefficients among all variables

\begin{tabular}{|c|c|c|c|c|c|c|c|c|c|}
\hline & & 1 & 2 & 3 & 4 & 5 & 6 & 7 & 8 \\
\hline 1 & PIL & - & $-0.092^{\star * *}$ & $0.034^{*}$ & $0.147^{* * *}$ & 0.006 & $0.138^{\star \star \star}$ & 0.013 & $-0.342^{* * *} \dagger$ \\
\hline 2 & Tobacco consumption & & - & $-0.067^{\star \star *}$ & $-0.203^{\star \star *}$ & $-0.144^{\star * *}$ & $-0.172^{\star \star *}$ & $0.065^{\star \star *}$ & $0.038^{*}$ \\
\hline 4 & Education & & & & - & $0.076^{\star \star \star}$ & $0.323^{\star \star \star}$ & -0.019 & -0.023 \\
\hline 5 & Marital status & & & & & - & $0.257^{* * *}$ & -0.003 & $-0.054^{\star * *}$ \\
\hline 7 & Alcohol use & & & & & & & - & -0.006 \\
\hline 8 & Psychological distress (K6) & & & & & & & & - \\
\hline
\end{tabular}

Spearman's rank correlation coefficients except a correlation between continuous variables (PIL and K6).

Bold: Correlation coefficient is statistically significant.

${ }^{\star} \mathrm{P}<0.05 ;{ }^{\star \star} \mathrm{P}<0.01 ;{ }^{\star \star \star} \mathrm{P}<0.001$.

†Pearson correlation coefficient.

PIL, purpose in life. 
Table 3 Logistic regression coefficients for odds of tobacco use, with and without potential confounding variables

\begin{tabular}{|c|c|c|c|c|c|c|c|c|}
\hline & \multicolumn{2}{|l|}{ Model 1} & \multicolumn{2}{|l|}{ Model 2} & \multicolumn{2}{|l|}{ Model 3} & \multicolumn{2}{|l|}{ Model 4} \\
\hline & OR $(95 \% \mathrm{Cl})$ & $P$ values & OR $(95 \% \mathrm{Cl})$ & $P$ values & OR $(95 \% \mathrm{Cl})$ & $P$ values & OR (95\% Cl) & $P$ values \\
\hline Purpose in life & $\begin{array}{l}0.71 \\
(0.63 \text { to } 0.80)\end{array}$ & $<0.001$ & $\begin{array}{l}0.81 \\
(0.71 \text { to } 0.91)\end{array}$ & 0.001 & $\begin{array}{l}0.80 \\
(0.71 \text { to } 0.91)\end{array}$ & $<0.001$ & $\begin{array}{l}0.80 \\
(0.70 \text { to } 0.91)\end{array}$ & 0.001 \\
\hline Age & & & $\begin{array}{l}0.98 \\
(0.95 \text { to } 1.00)\end{array}$ & 0.061 & $\begin{array}{l}0.97 \\
(0.95 \text { to } 1.00)\end{array}$ & 0.043 & $\begin{array}{l}0.97 \\
(0.95 \text { to } 1.00)\end{array}$ & 0.044 \\
\hline Education & & & $\begin{array}{l}0.44 \\
(0.38 \text { to } 0.52)\end{array}$ & $<0.001$ & $\begin{array}{l}0.45 \\
(0.38 \text { to } 0.52)\end{array}$ & $<0.001$ & $\begin{array}{l}0.45 \\
(0.38 \text { to } 0.52)\end{array}$ & $<0.001$ \\
\hline Marital status & & & $\begin{array}{l}0.41 \\
(0.27 \text { to } 0.62)\end{array}$ & $<0.001$ & $\begin{array}{l}0.41 \\
(0.27 \text { to } 0.63)\end{array}$ & $<0.001$ & $\begin{array}{l}0.41 \\
(0.27 \text { to } 0.63)\end{array}$ & $<0.001$ \\
\hline Family income & & & $\begin{array}{l}0.71 \\
(0.62 \text { to } 0.82)\end{array}$ & $<0.001$ & $\begin{array}{l}0.71 \\
(0.62 \text { to } 0.81)\end{array}$ & $<0.001$ & $\begin{array}{l}0.71 \\
(0.62 \text { to } 0.81)\end{array}$ & $<0.001$ \\
\hline Alcohol use & & & & & $\begin{array}{l}1.18 \\
(1.10 \text { to } 1.28)\end{array}$ & $<0.001$ & $\begin{array}{l}1.18 \\
(1.10 \text { to } 1.28)\end{array}$ & $<0.001$ \\
\hline
\end{tabular}

to the covariates in the fully adjusted model, educational attainment, marital status and family annual income were inversely associated with tobacco use. There was a positive association between tobacco use and frequency of alcohol consumption. Psychological distress was not associated with tobacco use.

Association between PIL and amount of tobacco consumption Figure 1 shows the ORs for smoking consumption, produced by multinomial logistic regressions comparing light and moderate to heavy smoking against the no smoking reference category. Without any adjustment (model 5), PIL was inversely associated with both light and moderate to heavy smoking (light smoking: $\mathrm{OR}=0.77$, 95\% CI: 0.67 to $0.89, \mathrm{p}<0.001$; moderate to heavy smoking: $\mathrm{OR}=0.62,95 \% \mathrm{CI}: 0.52$ to $0.74, \mathrm{p}<0.001)$. The ORs remained significant after adjusting for socioeconomic covariates (model 6: light smoking: $\mathrm{OR}=0.86$, 95\% CI: 0.74 to $1.00, \mathrm{p}=0.046$; moderate to heavy smoking: $\mathrm{OR}=0.72,95 \% \mathrm{CI}$ : 0.59 to $0.87, \mathrm{p}<0.001)$ and further adjustment for alcohol consumption (model 7: light smoking: $\mathrm{OR}=0.86,95 \% \mathrm{CI}$ : 0.74 to $0.99, \mathrm{p}=0.041$; moderate to heavy smoking: $\mathrm{OR}=0.71,95 \% \mathrm{CI}: 0.59$ to $0.87, \mathrm{p}<0.001)$. Adjusting further for psychological

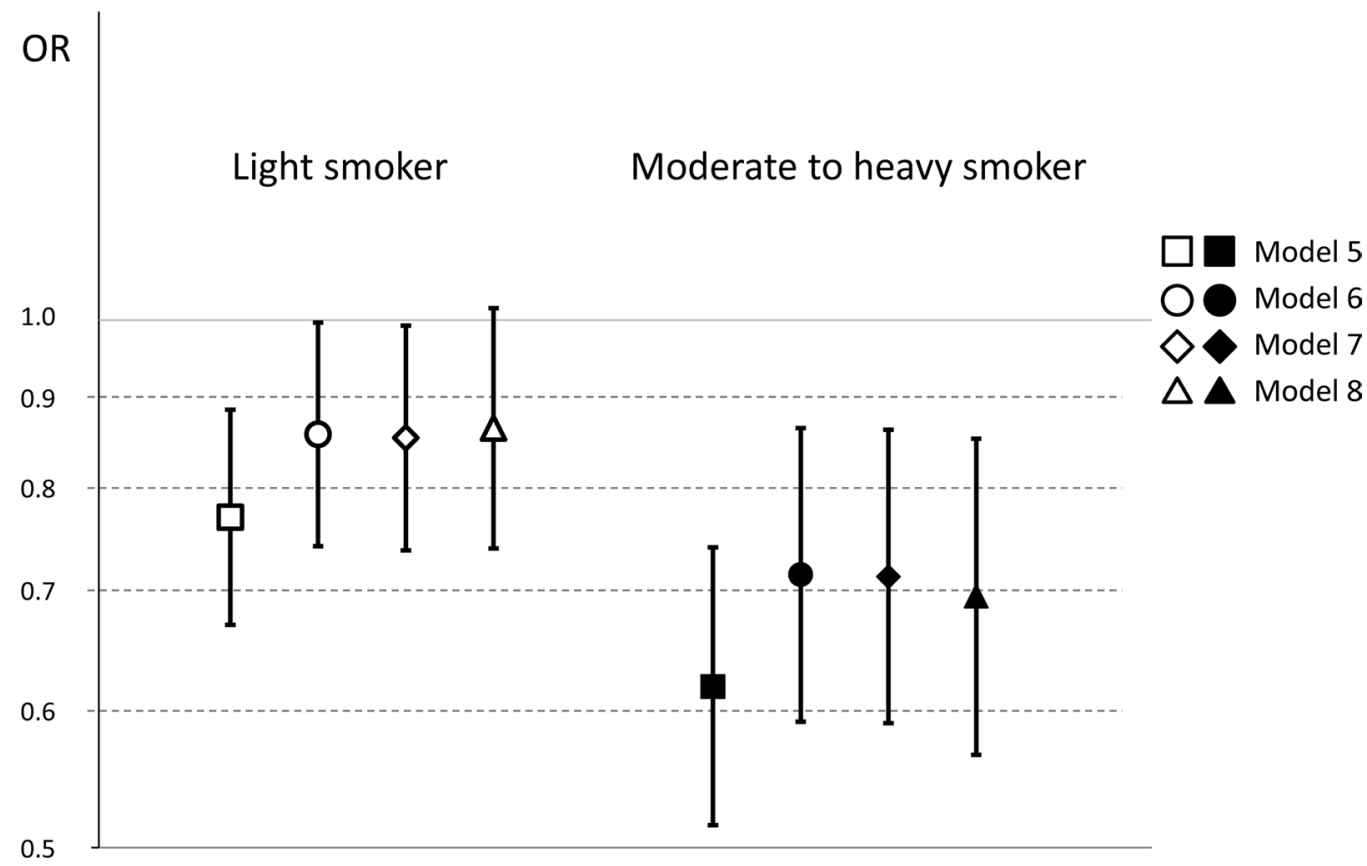

Figure 1 ORs for purpose in life from multinomial logistic regression analysis predicting smoking consumption (reference: non-smoker) with and without potential confounding variables. Model 5: without any adjustment; model 6: adjusting for socioeconomic covariates (educational attainment and family income); model 7: adjusting for socioeconomic covariates and alcohol consumption; model 8: adjusting for socioeconomic covariates, alcohol consumption and psychological distress. 
distress (model 8), the association between PIL and light smoking was not significant $(\mathrm{OR}=0.87,95 \% \mathrm{CI}$ : 0.74 to $1.02, \mathrm{p}=0.079)$. On the other hand, the OR for moderate to heavy smoking was not attenuated after adjustment for any of the aforementioned variables $(\mathrm{OR}=0.70,95 \% \mathrm{CI}$ : 0.57 to $0.86, \mathrm{p}<0.001$; see figure 1$)$.

\section{DISCUSSION}

In a community-based sample of mothers in early-middle age, we found that PIL was inversely associated with tobacco use after controlling for age, education, marital status, family income and alcohol use. Importantly, this was also the case even after taking psychological distress into account. PIL was also inversely associated with the risk of moderate to heavy tobacco consumption even after controlling for covariates. This result is consistent with that of a previous study on a community sample in Hungary. ${ }^{37}$ We confirmed the association between PIL and tobacco use with a large population-based sample of women in early midlife in Japan.

It is possible that individuals with higher PIL are likely to invest in healthy behaviours because they feel that their lives are meaningful, have a greater will to live and, therefore, are more proactive in taking care of their health ${ }^{21}$ (eg, by the avoidance of smoking). They may also be motivated to acquire knowledge regarding health maintenance (ie, the knowledge about how detrimental smoking is). In contrast, since those low in PIL lack a high sense of life's meaningfulness, it may seem pointless for them to protect their health, and they may prefer short-term gratification, such as that obtained through tobacco use.

The association between PIL and tobacco use was robust even when controlling for psychological distress. It may suggest a relationship between a lack of eudaemonic wellbeing (PIL) and tobacco use, rather than a relationship between ill-being (psychological distress) and tobacco use. Mental well-being and mental illness are correlated but belong to separate continua, with well-being referring to the presence of positive feelings and positive functioning, rather than just the absence of mental illness. ${ }^{55} 56$

The present results suggest that increasing PIL may be a valuable target of intervention for reducing tobacco use, as well as for reducing substance abuse. ${ }^{32}$ PIL is modifi$a_{b l e}^{5758}$ and increasing awareness of one's values or longterm goals in life could increase the sense of PIL. ${ }^{59} 60 \mathrm{~A}$ systematic review indicated that positive psychological intervention had an impact on improving psychological well-being, ${ }^{61}$ as well as a meta-analysis showed that behavioural intervention had a moderate effect on improving psychological well-being including PIL. ${ }^{62} \mathrm{~A}$ new community-based group intervention to promote psychological well-being has been developed and had a positive effect of improving PIL. ${ }^{63}$ Promotion focusing on increasing PIL might be effective in reducing tobacco use in public settings.

This study is limited, of course, in its capacity to determine causality, since the data were cross-sectional. Longitudinal studies should be conducted in order to determine whether PIL has a role in tobacco use. We are currently conducting a subsequent longitudinal cohort study (Tokyo Teen Cohort Study), which will further clarify causality between PIL and tobacco use among mothers. The sample was limited only to mothers and we could not examine the association among early-middle-aged women without children. Further studies including them would be needed. Additionally, given that parental smoking, especially maternal smoking, is the major determinant of passive smoking ${ }^{6}$ and smoking initiation $^{7}$ in children, follow-up studies should examine the transgenerational effects of mothers' tobacco use on the initiation of smoking in their children. The relatively low response rate (43.8\%) was also a limitation of the study. A recent study indicated that response rates of national cross-sectional surveys in Japan have declined in the recent decade (from around $70 \%$ to $50 \%$ ) ${ }^{64}$ One reason would be that many apartment buildings in Tokyo have recently adopted an automated system that enables residents talk with visitors at the locked gate through video. It allows potential respondents to make a decision of refusing participation without having a face-to-face encounter with the field worker. ${ }^{64}$ In future study, we should consider how to overcome this obstacle to achieve higher response rate in general population survey in Tokyo.

In summary, in a large community-based study, we found that high PIL is associated with lower consumption of tobacco among mothers, after controlling for a range of potential confounds, including psychological distress. Our hypothesis, that PIL is independently and inversely associated with tobacco use, was therefore confirmed. This study may contribute to our understanding of the psychology of smoking behaviour and shed light on the target for intervention to reduce tobacco use among early midlife mothers.

\section{Author affiliations}

${ }^{1}$ Department of Psychiatry and Behavioral Science, Tokyo Metropolitan Institute of Medical Science, Tokyo, Japan

${ }^{2}$ Department of Neuropsychiatry, Graduate School of Medicine, The University of Tokyo, Tokyo, Japan

${ }^{3}$ University of Tokyo Institute for Diversity \& Adaptation of Human Mind (UTIDAHM), The University of Tokyo, Tokyo, Japan

${ }^{4}$ Department of Psychiatry, Teikyo University School of Medicine, Tokyo, Japan ${ }^{5}$ Department of Psychological Medicine, Institute of Psychiatry, Psychology \& Neuroscience, King's College London, London, UK

${ }^{6}$ MRC Unit for Lifelong Health and Aging, University College London, London, UK ${ }^{7}$ School of Advanced Science, SOKENDAl (The Graduate University for Advanced Studies), Kanagawa, Japan

Contributors YM, SY, SA, SKo, AN, MH-H and KK involved in launching and maintaining the survey. SF, SKa and KE have mainly contributed to data collection. MN, SLH and MR mainly contributed to design the study and propose the analysis and interpretation of data. YM and SY wrote the first draft of the manuscript and all the other authors have critically reviewed it. All authors approved the final version of the manuscript.

Funding This study was supported by a Japan Scientific Research Grant on an Innovative Area from the Ministry of Education, Culture, Sports, Science and Technology (MEXT KAKENHI 23118002); a Japan Scientific Research Grant on an Innovative Area from the Japan Society for the Promotion of Science (JSPS KAKENHI 16H06395, 16H06398, 16K21720); a Grant-in-Aid for Challenging Exploratory Research from the Japan Society for the Promotion of Science (JSPS KAKENHI 16K13499); a Grant-in-Aid for Scientific Research (B) from the Japan 
Society for the Promotion of Science (JSPS KAKENHI 16H03745) and a Tokyo Metropolitan Institute of Medical Science Project Grant (Kokoronokenko H27-H31). Competing interests None declared.

Patient consent Not required.

Ethics approval This study was approved by the ethics committees of the following three institutes: three research institutes: Tokyo Metropolitan Institute of Medical Science, The University of Tokyo and SOKENDAI (The Graduate University for Advanced Studies)

\section{Provenance and peer review Not commissioned; externally peer reviewed.}

Data sharing statement When applying to the research ethics committee for the data set, the authors did not request this to be released as public data. However, the data can be made available to all interested researchers on request to $\mathrm{Dr}$ Atsushi Nishida (nishida-at@igakuken.or.jp).

Open Access This is an Open Access article distributed in accordance with the Creative Commons Attribution Non Commercial (CC BY-NC 4.0) license, which permits others to distribute, remix, adapt, build upon this work non-commercially, and license their derivative works on different terms, provided the original work is properly cited and the use is non-commercial. See: http://creativecommons.org/ licenses/by-nc/4.0/

C Article author(s) (or their employer(s) unless otherwise stated in the text of the article) 2018. All rights reserved. No commercial use is permitted unless otherwise expressly granted.

\section{REFERENCES}

1. World Health Organization. WHO global report on mortality attributable to tobacco. Geneva: World Health Organization, 2012.

2. Funatogawa I, Funatogawa T, Yano E. Trends in smoking and lung cancer mortality in Japan, by birth cohort, 1949-2010. Bull World Health Organ 2013;91:332-40.

3. Lopez AD, Collishaw NE, Piha T. A descriptive model of the cigarette epidemic in developed countries. Tob Control 1994;3:242-7.

4. Gram IT, Sandin S, Braaten T, et al. The hazards of death by smoking in middle-aged women. Eur J Epidemiol 2013;28:799-806.

5. Pirie K, Peto R, Reeves GK, et al. The 21st century hazards of smoking and benefits of stopping: a prospective study of one million women in the UK. Lancet 2013;381:133-41.

6. Stiby Al, Macleod J, Hickman M, et al. Association of maternal smoking with child cotinine levels. Nicotine Tob Res 2013;15:2029-36.

7. Voorhees CC, Ye C, Carter-Pokras O, et al. Peers, tobacco advertising, and secondhand smoke exposure influences smoking initiation in diverse adolescents. Am J Health Promot 2011;25:e1-11.

8. Ryff CD. Happiness is everything, or is it? Explorations on the meaning of psychological well-being. J Pers Soc Psychol 1989;57:1069-81.

9. Boyle PA, Buchman AS, Barnes LL, et al. Effect of a purpose in life on risk of incident Alzheimer disease and mild cognitive impairment in community-dwelling older persons. Arch Gen Psychiatry 2010;67:304-10.

10. Kim ES, Sun JK, Park N, et al. Purpose in life and reduced risk of myocardial infarction among older U.S. adults with coronary heart disease: a two-year follow-up. J Behav Med 2013;36:124-33.

11. Kim ES, Sun JK, Park N, et al. Purpose in life and reduced incidence of stroke in older adults: 'The Health and Retirement Study'. J Psychosom Res 2013;74:427-32.

12. Yu L, Boyle PA, Wilson RS, et al. Purpose in life and cerebral infarcts in community-dwelling older people. Stroke 2015;46:1071-6.

13. Kim ES, Kawachi I, Chen Y, et al. Association between purpose in life and objective measures of physical function in older adults. JAMA Psychiatry 2017;74:1039-45.

14. Boyle PA, Barnes LL, Buchman AS, et al. Purpose in life is associated with mortality among community-dwelling older persons. Psychosom Med 2009;71:574-9.

15. Cohen $R$, Bavishi $C$, Rozanski $A$. Purpose in life and its relationship to all-cause mortality and cardiovascular events: a meta-analysis. Psychosom Med 2016;78:122-33.

16. Hill PL, Turiano NA. Purpose in life as a predictor of mortality across adulthood. Psychol Sci 2014;25:1482-6.

17. Koizumi M, Ito $\mathrm{H}$, Kaneko $\mathrm{Y}$, et al. Effect of having a sense of purpose in life on the risk of death from cardiovascular diseases. J Epidemiol 2008;18:191-6.

18. Krause N. Meaning in life and mortality. J Gerontol B Psychol Sci Soc Sci 2009;64:517-27.
19. Sone T, Nakaya N, Ohmori K, et al. Sense of life worth living (ikigai) and mortality in Japan: Ohsaki Study. Psychosom Med 2008;70:709-15.

20. Roepke AM, Jayawickreme E, Riffle OM. Meaning and health: a systematic review. Appl Res Qual Life 2014;9:1055-79.

21. Kim ES, Strecher VJ, Ryff CD. Purpose in life and use of preventive health care services. Proc Natl Acad Sci U S A 2014:111:16331-6.

22. Holahan CK, Holahan CJ, Suzuki R. Purposiveness, physical activity, and perceived health in cardiac patients. Disabil Rehabil 2008;30:1772-8.

23. Holahan CK, Suzuki R. Motivational factors in health promoting behavior in later aging. Act Adapt Aging 2006;30:47-60.

24. Hooker SA, Masters KS. Purpose in life is associated with physical activity measured by accelerometer. J Health Psychol 2016;21:962-71.

25. Conner TS, Brookie KL, Richardson AC, et al. On carrots and curiosity: eating fruit and vegetables is associated with greater flourishing in daily life. Br J Health Psychol 2015;20:413-27.

26. Piko BF, Brassai $L$. The role of individual and familial protective factors in adolescents' diet control. J Health Psychol 2009;14:810-9.

27. Irving J, Davis S, Collier A. Aging with purpose: systematic search and review of literature pertaining to older adults and purpose. Int $\mathrm{J}$ Aging Hum Dev 2017;85:403-37.

28. Boylan JM, Tsenkova VK, Miyamoto Y, et al. Psychological resources and glucoregulation in Japanese adults: findings from MIDJA. Health Psychol 2017;36:449-57.

29. Tsenkova VK, Love GD, Singer BH, et al. Socioeconomic status and psychological well-being predict cross-time change in glycosylated hemoglobin in older women without diabetes. Psychosom Med 2007;69:777-84.

30. Carroll S. Spirituality and purpose in life in alcoholism recovery. $J$ Stud Alcohol 1993;54:297-301.

31. Harlow LL, Newcomb MD, Bentler PM. Depression, self-derogation, substance use, and suicide ideation: lack of purpose in life as a mediational factor. J Clin Psychol 1986;42:5-21.

32. Martin RA, MacKinnon S, Johnson J, et al. Purpose in life predicts treatment outcome among adult cocaine abusers in treatment. J Subst Abuse Treat 2011;40:183-8.

33. Robinson EA, Cranford JA, Webb JR, et al. Six-month changes in spirituality, religiousness, and heavy drinking in a treatment-seeking sample. J Stud Alcohol Drugs 2007;68:282-90.

34. Smith $\mathrm{PH}$, Bessette AJ, Weinberger $\mathrm{AH}$, et al. Sex/gender differences in smoking cessation: a review. Prev Med 2016;92:135-40.

35. Cepeda-Benito A, Reynoso JT, Erath S. Meta-analysis of the efficacy of nicotine replacement therapy for smoking cessation: differences between men and women. J Consult Clin Psychol 2004:72:712-22.

36. Heckman CJ, Egleston BL, Hofmann MT. Efficacy of motivational interviewing for smoking cessation: a systematic review and metaanalysis. Tob Control 2010;19:410-6.

37. Konkolÿ Thege B, Bachner YG, Martos T, et al. Meaning in life: does it play a role in smoking? Subst Use Misuse 2009;44:1566-77.

38. Anda RF, Williamson DF, Escobedo LG, et al. Depression and the dynamics of smoking. a national perspective. JAMA 1990;264:1541-5.

39. Boden JM, Fergusson DM, Horwood LJ. Cigarette smoking and depression: tests of causal linkages using a longitudinal birth cohort. Br J Psychiatry 2010;196:440-6.

40. Breslau N, Peterson EL, Schultz LR, et al. Major depression and stages of smoking. a longitudinal investigation. Arch Gen Psychiatry 1998;55:161-6.

41. Glassman AH, Helzer JE, Covey LS, et al. Smoking, smoking cessation, and major depression. JAMA 1990;264:1546-9.

42. Kendler KS, Neale MC, MacLean CJ, et al. Smoking and major depression. a causal analysis. Arch Gen Psychiatry 1993;50:36-43.

43. Lawrence D, Mitrou F, Zubrick SR. Smoking and mental illness: results from population surveys in Australia and the United States. BMC Public Health 2009;9:285.

44. Leung J, Gartner C, Hall W, et al. A longitudinal study of the bidirectional relationship between tobacco smoking and psychological distress in a community sample of young Australian women. Psychol Med 2012;42:1273-82.

45. Moylan S, Jacka FN, Pasco JA, et al. Cigarette smoking, nicotine dependence and anxiety disorders: a systematic review of population-based, epidemiological studies. BMC Med 2012;10:123.

46. Pinquart M. Creating and maintaining purpose in life in old age: a meta-analysis. Ageing Int 2002;27:90-114.

47. Zika S, Chamberlain K. On the relation between meaning in life and psychological well-being. Br J Psychol 1992;83 (Pt 1):133-45.

48. Kanata S, Koike S, Ando S, et al. Enuresis and hyperactivityinattention in early adolescence: Findings from a population-based 
survey in Tokyo (Tokyo Early Adolescence Survey). PLoS One 2016;11:e0158786.

49. Yamasaki S, Ando S, Koike S, et al. Dissociation mediates the relationship between peer victimization and hallucinatory experiences among early adolescents. Schizophr Res Cogn 2016;4:18-23.

50. Kessler RC, Andrews G, Colpe LJ, et al. Short screening scales to monitor population prevalences and trends in non-specific psychological distress. Psychol Med 2002;32:959-76.

51. Amos A. Women and smoking. Br Med Bull 1996;52:74-89.

52. David A, Esson K, Perucic AM, et al. Tobacco use: equity and social determinants. In: Blas E, Kurup AS, eds. Equity, social determinants and public health programmes. Geneva: World Health Organization, 2010.

53. Hiscock R, Bauld L, Amos A, et al. Socioeconomic status and smoking: a review. Ann N Y Acad Sci 2012;1248:107-23.

54. Laaksonen M, Rahkonen O, Karvonen S, et al. Socioeconomic status and smoking. Eur J Public Health 2005;15:262-9.

55. Keyes $\mathrm{CL}$. The mental health continuum: from languishing to flourishing in life. J Health Soc Behav 2002;43:207-22.

56. Keyes CL. Mental illness and/or mental health? Investigating axioms of the complete state model of health. $J$ Consult Clin Psychol 2005;73:539-48.
57. Ryff CD. Psychological well-being revisited: advances in the science and practice of eudaimonia. Psychother Psychosom 2014;83:10-28.

58. Ryff $C D$. The benefits of purposeful life engagement on later-life physical function. JAMA Psychiatry 2017;74:1046-7.

59. Dolan SL, Rohsenow DJ, Martin RA, et al. Urge-specific and lifestyle coping strategies of alcoholics: relationships of specific strategies to treatment outcome. Drug Alcohol Depend 2013;128:8-14.

60. Miller WR, Rollnick S. Motivational interviewing: helping people change. Third ed. New York: Guilford Press, 2012.

61. Sutipan P, Intarakamhang U, Macaskill A. The impact of positive psychological interventions on well-being in healthy elderly people. $J$ Happiness Stud 2017;18:269-91.

62. Weiss LA, Westerhof GJ, Bohlmeijer ET. Can we increase psychological well-being? The effects of interventions on psychological well-being: a meta-analysis of randomized controlled trials. PLoS One 2016;11:e0158092.

63. Friedman EM, Ruini C, Foy R, et al. Lighten UP! A community-based group intervention to promote psychological well-being in older adults. Aging Ment Health 2017;21:199-205.

64. Rindfuss RR, Choe MK, Tsuya NO, et al. Do low survey response rates bias results? Evidence from Japan. Demogr Res 2015;32:797-828. 